\title{
Segregation of mitochondrial DNA (mtDNA) in human oocytes and in animal models of mtDNA disease: clinical implications
}

\author{
Joanna Poulton and David R. Marchington \\ University of Oxford Department of Paediatrics, John Radcliffe Hospital, Oxford OX3 9DU, UK
}

\begin{abstract}
Mitochondrial DNA ( $m t D N A)$ is almost entirely maternally inherited. Thousands of copies of mtDNA are present in every nucleated cell and in most normal individuals these are virtually identical (homoplasmy). mtDNA diseases may be caused by mutations in either mitochondrial or nuclear genes and, hence, give rise to maternal or autosomal patterns of inheritance. Antenatal diagnosis of mitochondrial diseases based on chorionic villous sampling is available for Mendelian disorders and the syndromes caused by mutations at bp 8993 (associated with Leigh's syndrome and neurogenic weakness, ataxia and retinitis pigmentosa (NARP)). However, prenatal diagnosis of many other maternally inherited $\mathrm{mtDNA}$ diseases is less reliable because it is not possible to predict with confidence the way in which heteroplasmic mtDNA mutations segregate within tissues and find clinical expression. This review focuses on the substantial progress in genetics that has been made recently, and on the management options that clinicians can offer to families.
\end{abstract}

Despite substantial advances in mitochondrial genetics, prenatal diagnosis has not been available for most mitochondrial DNA (mtDNA) diseases. Hence, unaffected female relatives of patients with a maternally inherited mtDNA point mutation who have a low risk of transmitting the disorder may choose not to have children because of their perception of the risk of recurrence. However, this situation is changing.

\section{The biology of MtDNA}

mtDNA encodes polypeptides involved in electron transport (Attardi and Schatz, 1988) and is maternally inherited. Unlike nuclear DNA, in which there are only two copies of each gene per cell, thousands of copies of mtDNA are present in every nucleated cell. Normal individuals are homoplasmic (that is, virtually all of their mtDNAs are identical). Heteroplasmy (the presence of both normal and mutant mtDNA in a single individual) is present in most mtDNA diseases, so that the proportion of mutant mtDNA in any cell or tissue may range from $0 \%$ to $100 \%$.

The polypeptides encoded by mtDNA are all subunits of the mitochondrial respiratory chain. This is a highly complex array of multimeric enzymes that generate ATP. Most of these are encoded in the nucleus, as are many mitochondrial proteins (Fig. 1). Hence, mitochondrial disease can result from mutations in autosomal and mitochondrial genes (Table 1). Potentially, there are a large number of mitochondrial diseases with a Mendelian pattern of inheritance. There have been a number of studies on

Email: joanna.poulton@paediatrics.ox.ac.uk the cloning of nuclear genes for mitochondrial diseases (Smeitink and van den Heuvel, 1999) and on prenatal diagnosis in affected families. The focus of this review is on the genetic advice given to individuals with maternally inherited mtDNA disease.

\section{Heteroplasmy and progressive mtDNA disease}

Heteroplasmy with variation in the amount of mutant mtDNA between tissues is common in mitochondrial diseases. There appears to be a threshold effect and symptoms arise only from tissues with a high amount of mutant mtDNA. Accumulation of mutant mtDNAs in affected tissues is an explanation for the progressive nature of these disorders (Poulton et al., 1995; Weber et al., 1997). For example, in one patient the proportion of a mutant mtDNA: (i) increased successively in sequential muscle biopsies; (ii) was approximately zero in cultured cells; and (iii) decreased after local muscle damage, because the mutant content in satellite cells, responsible for regeneration, was lower than in the mature muscle fibres. Most mtDNA is maternally inherited. When there is a point mutation difference between a mother and her offspring, there may be complete switching of mtDNA type in a single generation: that is, each was homoplasmic with regard to that base. As oocytes contain at least 100000 mtDNAs and yet the mutation probably only occurs once, there must be a restriction followed by an amplification in the number of mtDNAs, whereby the mutant mtDNA becomes the mitochondrial founder for the child. We refer to this as a genetic 'bottleneck'. After birth, there may also be segregation of mtDNAs so that affected individuals have different amounts of mutant mtDNA in different tissues, 


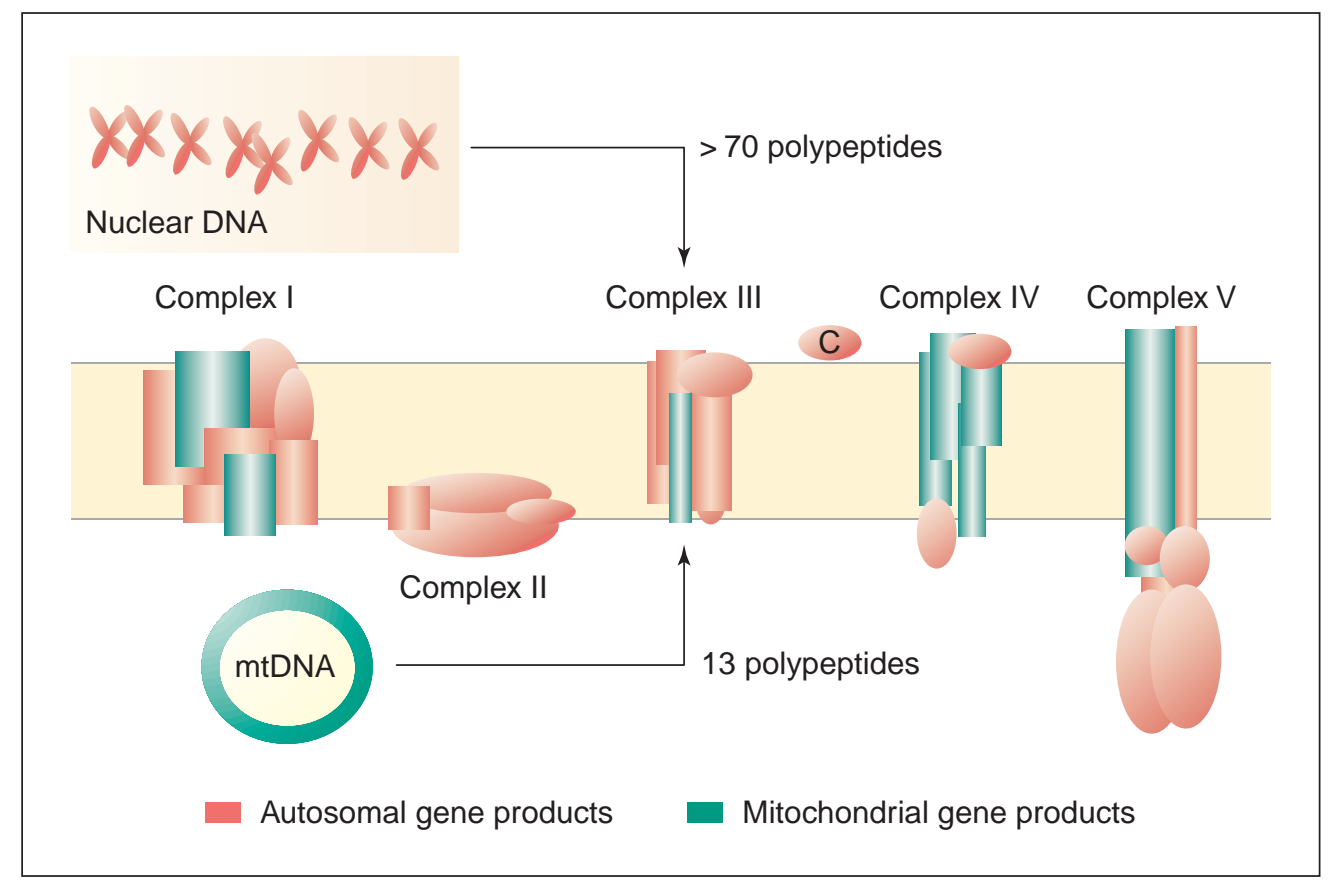

Fig. 1. The mitochondrial respiratory chain. Reduced co-factors such as NADH and flavoproteins (such as found in succinate dehydrogenase) are reoxidized by the mitochondrial respiratory chain. Electrons are donated to the MRC and subsequently pass from complex to complex down an energy gradient. Sufficient energy is generated at three steps (complexes I, III and IV) to drive the extrusion of protons $\left(\mathrm{H}^{+}\right)$ that cannot re-enter the inner membrane. This creates an electrochemical gradient, which is discharged back into the mitochondrion via complex $\mathrm{V}$ and the energy this generates is used to drive phosphorylation of ADP to ATP. Thus, substrate oxidation is linked to phosphorylation of ADP (oxidative phosphorylation). The final electron acceptor is molecular oxygen. C: cytochrome c.

Table 1. Mitochondrial DNA diseases classified by mode of inheritance

\begin{tabular}{|c|c|c|c|c|}
\hline & Type of DNA defect & Example of disorder & Protein/mechanism involved & OMIM number \\
\hline Sporadic & Major rearrangements of mtDNA & KSS, CPEO, Pearson's & mtDNA protein synthesis & KSS \#530000 \\
\hline Maternal & Point mutations of mtDNA & $\begin{array}{l}\text { MELAS, MERRF } \\
\text { NARP, LHON, familial } \\
\text { duplications }\end{array}$ & $\begin{array}{l}\text { mtDNA protein synthesis } \\
\text { In LHON complex I activity } \\
\text { reduced }\end{array}$ & MELAS \#540000 \\
\hline $\begin{array}{r}\text { Autosomal } \\
\text { dominant }\end{array}$ & mtDNA homeostasis & $\begin{array}{l}\text { Multiple deletions } \\
\text { mtDNA depletion }\end{array}$ & $\begin{array}{l}\text { POLG, ANT1, Twinkle } \\
\text { TK2, DGUOK }\end{array}$ & $\begin{array}{l}\# 157640 \\
\# 251880\end{array}$ \\
\hline \multirow[t]{2}{*}{$\begin{array}{l}\text { Autosomal } \\
\text { recessive }\end{array}$} & $\begin{array}{l}\text { Deficiencies in specific } \\
\text { MRC subunits }\end{array}$ & Complex I & $\begin{array}{l}\text { Flavoproteins: NDUFV1 } \\
\text { Iron sulphur protein: NDUFS4 } \\
\text { Electron transfer proteins: } \\
\text { NDUFS7 and NDUFS8 }\end{array}$ & $\begin{array}{l}\text { Complex } 1 \\
\# 252010\end{array}$ \\
\hline & $\begin{array}{l}\text { Assembly defect } \\
\text { mtDNA homeostasis }\end{array}$ & $\begin{array}{l}\text { Complex II } \\
\text { Complex IV/COX deficiency } \\
\text { mtDNA depletion } \\
\text { MNGIE }\end{array}$ & $\begin{array}{l}\text { Flavoprotein SDHA } \\
\text { SURF-1 } \\
\text { TK2, DGUOK } \\
\text { Thymidine phosphorylase }\end{array}$ & $\begin{array}{l}* 600857 \\
* 185620 \\
\# 251880 \\
\# 603041\end{array}$ \\
\hline X-linked & & $\begin{array}{l}\text { Pyruvate dehydrogenase } \\
\text { deficiency }\end{array}$ & $\begin{array}{l}\text { Pyruvate dehydrogenase } \\
\text { complex }\end{array}$ & *312170 \\
\hline
\end{tabular}

The more common mitochondrial and autosomal genetic disorders. Where appropriate, Online Mendelian Inheritance in Man (OMIM) numbers are given for further reference.

KSS: Kearns-Sayre phenotype; CPEO: chronic progressive external ophthalmoplegia; MELAS: mitochondrial encephalomyopathy, lactic acidosis and strokelike episodes; MERRF: myoclonic epilepsy and ragged-red fibre disease; NARP: neurigenic weakness, ataxia and retinitis pigmentosa; COX: cytochrome c oxidase; LHON: Leber's hereditary optic neuropathy; POLG: DNA polymerase gamma; ANT1: adenine nucleotide transporter 1; DGUOK: deoxyguanosine kinase; TK2: thymidine kinase 2; NDUF: NADH-ubiquinone oxidoreductase flavoprotein; NDUFS: NADH-ubiquinone oxidoreductase Fe-S protein; SDHA: succinate dehydrogenase complex, subunit A, flavoprotein; MNGIE: myo-neural gastrointestinal encephalopathy. 


\begin{tabular}{|c|c|c|c|c|}
\hline & & $\begin{array}{l}\text { Number } \\
\text { of cells }\end{array}$ & $\begin{array}{l}\text { Number of } \\
\text { mitochondria } \\
\text { per cell }\end{array}$ & $\begin{array}{l}\text { Developmental } \\
\text { stage }\end{array}$ \\
\hline Primordial germ cell & (0) & $\sim 45$ & 10 & 3 week fetus \\
\hline Oogonium & & 520000 & 200 & 9 week fetus \\
\hline $\begin{array}{l}\text { Diplotene primary } \\
\text { oocyte }\end{array}$ & & $\sim 7000000$ & 5000 & 20 week fetus \\
\hline Primordial follicle & & $\sim 2000000$ & 10000 & Neonate \\
\hline $\begin{array}{l}\text { Mature preovulatory } \\
\text { oocyte }\end{array}$ & & $\sim 300000$ & $>100000$ & Adult \\
\hline
\end{tabular}

Fig. 2. Human oogenesis. There is considerable fluctuation in the number of cells and number of mitochondria per cell during human oogenesis. The mitochondrial bottleneck has been proposed to occur at a very early stage between the primordial germ cell stage and oogonia. A small number of primordial germ cells migrate to the gonad and are rapidly expanded to a large population of oocytes (approximately $7 \times 10^{6}$ ), followed by large scale atresia beginning before birth, such that at birth the population has already decreased to approximately $2 \times 10^{6}$. By middle age this has decreased to approximately 25000 .

different cells within a tissue and perhaps even different mitochondria within an individual cell. However, in practice, the mean amount of mutant mtDNA in the offspring and oocytes is likely to be close to that of the mother (Marchington et al., 1998; Brown et al., 2001).

\section{Studies of the mitochondrial bottleneck}

We have investigated the mitochondrial bottleneck in normal oocytes from couples in our IVF clinic referred for male infertility, using naturally occurring length variation in the large non-coding region of mtDNA. This region of mtDNA deviates from the rule that homoplasmy is the norm, as some individuals are heteroplasmic for different length variants. There is little or no difference in the frequency distribution of length variants between several different tissues from any normal individual. We studied a heteroplasmic length variant in oocytes from controls and from a patient with a pathogenic mtDNA mutation and showed that segregation of founder mtDNA molecules probably occurs well before the oocytes are mature (Marchington et al., 1997). This stage of egg development occurs in human females in fetal life, before about week 20 of gestation (Fig. 2). By the time oocytes are used in reproduction, the population of oocytes remaining may be quite different from those initially present. A similar result was obtained with oocytes from a woman with the A3243G mutation (Brown et al., 2001). No such segregation occurred in multiple samples of placenta (D. R. Marchington and J. Poulton, unpublished). Further studies are essential, as the apparent size of the bottleneck appears to depend on the mtDNA mutation. For example, segregation was very marked in a family carrying the mtDNA mutation at position T8993G (Blok et al., 1997) compared with a patient with the mtDNA rearrangement (Marchington et al., 1998). Hence, the confidence limits for the risk of recurrence, or the uncertainty of inheritance, are extremely high in the former.

Four research groups have recently constructed heteroplasmic mouse models of mtDNA segregation by introducing donor cytoplasm into a fertilized recipient mouse egg (Jenuth et al., 1996; Laipis, 1996; Meirelles and Smith, 1997; White, 1999). Analysis of developing female germ cells demonstrated that the major component of the bottleneck occurs between the primordial germ cell and primary oocyte stage. These data imply that the major component of the bottleneck has occurred well before the time that oocytes are mature.

If mutant mtDNA remains uniformly distributed among individual cells of the embryo, it should be possible to assess the amount of mutant mtDNA prenatally, by sampling either chorionic villus or preimplantation embryos. In a recent study, every blastomere in preimplantation embryos derived from heteroplasmic mouse oocytes (Jenuth et al., 1996; Molnar and Shoubridge, 1999) contained very similar amounts of mutant mtDNA. A comparable result was obtained when ooplasm, polar bodies and blastomeres of a preimplantation embryo from a woman with the A3243G mutation were analysed (R.P. Jansen, personal communication). 
Few carrier/affected fetuses have been analysed for load of mutant mtDNA in different tissues. However, the limited existing data from studies on human fetuses or neonates with pathogenic mtDNA mutations also indicate that mutant mtDNAs do not segregate much during embryogenesis (Harding et al., 1992; Suomalainen et al., 1993; Matthews et al., 1994). In two of the animal models of heteroplasmic mtDNA segregation, the proportion of each mtDNA variant was uniform in all tissues of the fetuses analysed. Taken together, these studies indicate that a major bottleneck occurs during oogenesis and that mtDNA does not segregate much during embryogenesis.

However, in two of these experiments there was tissuespecific, directional selection for different mtDNA genotypes in the same animal (Jenuth et al., 1997; White, 1999). These studies used non-pathogenic mtDNA variants but are consistent with the limited studies that have been performed on pathogenic variants.

There are now mouse models of two different groups of detrimental mtDNA mutations but there have not been extensive pedigrees for the study of mtDNA segregation or phenotypes that are classical for mtDNA disease in either group. Mitochondria harbouring an mtDNA mutation in a ribosomal gene that confers chloramphenicol resistance and a respiratory defect in cultured cells were introduced into mouse embryonic stem cells and used to create chimaeric mice. Chloramphenicol resistance mtDNA was detectable in all of ten types of tissue in seven chimaeric mice, but not in all tissues in all of the mice that were analysed. This finding demonstrated that transmitochondrial embryonic stem cells are still pluripotent and indicated that this method can be used to generate mice that are chimaeric and potentially transgenic for mtDNA mutants (Marchington et al., 1999). Another group obtained germline transmission using a different chloramphenicol resistance mutation but found that the phenotype was severe and resulted in fetal death (Sligh et al., 2000). Survivors had myopathy and dilated cardiomyopathy and the oldest pup died at day 11 after birth. Inoue et al. (2000) generated transmitochondrial mice with rearranged mtDNA. Unlike human phenotypes, in which mtDNA deletions are usually sporadic, transmission of this rearranged mtDNA followed a maternal inheritance pattern. There was histological but not clinical evidence of muscle involvement and the main cause of death was renal, a rare occurrence in human diseases. Therefore, these studies are not exact parallels of human mtDNA disease.

\section{Prenatal diagnosis of mtDNA disease}

Precise recommendations regarding prenatal diagnosis for maternally inherited mtDNA diseases have been formulated at a recent European Neuro Muscular Centre (ENMC) workshop (Poulton and Turnbull, 2000). These recommendations depend on the particular mutation and, hence, the recommendation of the workshop was that specialist advice should be sought in counselling these patients.
Currently, the options open to women with mtDNA disease are: (i) oocyte donation: in practice, there is a limited supply of donors and maternal relatives such as sisters are high risk; (ii) preimplantation diagnosis: current data indicate that the varied tissue distribution of mtDNA mutants which is found postnatally has not developed in preimplantation embryos in which heteroplasmic mtDNA is uniformly distributed between blastomeres (Jenuth et al., 1996; Molnar and Shoubridge, 1999); (iii) chorionic villous sampling: little is known regarding the tissue distribution of mtDNA mutants in the developing fetus, and what evidence there is indicates that the mutant load in extraembryonic tissues probably reflects that of the fetus (Wardell et al., 1999; White et al., 1999a); and (iv) there may be many asymptomatic maternal relatives who feel unable to risk having children because of these uncertainties. Estimations of the risks of recurrence on the basis of blood content of mutant mtDNA are reasonable in some types of mutation but may be very inaccurate in others, when content of mutant mtDNA is not representative of other tissues or germline content of mutant mtDNA (Chinnery et al., 1998). We are using oocyte sampling to estimate the risks of recurrence more accurately. This approach is intended specifically for counselling before conception, not for implantation of oocytes. All the oocytes from a cycle of superovulation are taken and analysed as a representative sample of the oocyte population as a whole. This has been particularly useful in families with a single affected child where the absence of mutant mtDNA in the mother's blood may be falsely reassuring. Although the amount of mutant mtDNA in oocytes sampled after superovulation may give the best estimate for the likely content in the child, it is not certain that they are truly representative of the oocytes that might develop into live babies. We have used this approach particularly in 'private mutations', in which only a single family has been reported and so there are minimal historical data on which to base estimates of the risk of recurrence.

\section{Requirements for mtDNA prenatal diagnosis}

A major problem for genetic counselling is that the correlation between phenotypic severity and amount of mutant is poor in many mtDNA diseases. Prenatal diagnosis would be easy if there were: (i) a close correlation between load of mutant mtDNA and disease severity; (ii) uniform distribution of mutant in all tissues; and (iii) no change in mutant load with time. These criteria are fulfilled in families with mutations at bp 8993 but not in most mtDNA disorders (Chinnery et al., 1997, 1998; White et al., 1999a,b).

The risk of recurrence for a severe phenotype based on maternal content of mutant have been estimated in a handful of disorders, most accurately for mutations at bp 8993 (White et al., 1999a). Such data are limited by the accuracy with which the amount of mutant mtDNA in oocytes can be predicted from the tissues available for analysis. In the case of mitochondrial encephalomyopathy, 
lactic acidosis and stroke-like episodes (MELAS) as a result of mutations at bp 3243, blood content of mutant mtDNA may be very misleading. We suggest that there are situations where genetic counselling before conception on the basis of oocyte sampling could be useful. This should probably be restricted to women in whom prenatal diagnosis can subsequently be performed.

Preimplantation diagnosis has some theoretical advantages but is not widely available in the UK. As with all IVF procedures, the rate of achieving pregnancy is substantially lower than for natural conception. Therefore, it is most applicable to women with a very high risk of recurrence.

Chorionic villous sampling has been performed successfully in several women carrying the neurogenic weakness, ataxia and retinitis pigmentosa (NARP) mutation. In all cases, the mutant load was either high or low, enabling accurate predictions. However, caution is needed for other mtDNA disorders in which the correlation between severity and mutant load is less precise. As with all of the options, there is a risk that chorionic villous sampling may be unhelpful where the mutant load has an intermediate value.

We anticipate that our understanding of the transmission genetics and segregation of mtDNA mutants will be revolutionized by new findings based on the animal models of mtDNA disease currently being developed and that prenatal diagnosis will become routine thereafter.

\section{References}

Key references are identified by asterisks.

Attardi G and Schatz G (1988) Biogenesis of mitochondria Annual Reviews of Cell Biology 4 289-333

Blok R, Cook D, Thorburn D and Dahl H (1997) Skewed segregation of the mtDNA nt 8993 (T->G) mutation in human oocytes American Journal of Human Genetics 60 1495-1501

Brown DT, Samuels DC, Michael EM, Turnbull DM and Chinnery PF (2001) Random genetic drift determines the level of mutant mtDNA in human primary oocytes American Journal of Human Genetics 68 533-536

Chinnery PF, Howell N, Lightowlers R and Turnbull DM (1997) Molecular pathology of MELAS and MERRF: the relationship between mutation load and clinical phenotype Brain 120 1713-1721

Chinnery PF, Howell N, Lightowlers R and Turnbull DM (1998) The inheritance of MELAS and MERRF: the relationship between maternal mutation load and the frequency of affected offspring Brain 121 1889-1894

Harding AE, Holt IJ, Sweeney MG, Brockington M and Davis MB (1992) Prenatal diagnosis of mitochondrial DNA8993 T-G disease American Journal of Human Genetics 50 629-633

Inoue K, Nakada K, Ogura A, Isobe K, Goto Y, Nonaka I and Hayashi JI (2000) Generation of mice with mitochondrial dysfunction by introducing mouse mtDNA carrying a deletion into zygotes Nature Genetics 26 176-181

*Jenuth J, Peterson A, Fu K and Shoubridge E (1996) Random genetic drift in the female germline explains the rapid segregation of mammalian mitochondrial DNA Nature Genetics 14 146-151

Jenuth J, Peterson A and Shoubridge E (1997) Tissue-specific selection for different mtDNA genotypes in heteroplasmic mice Nature Genetics 16 93-95

Laipis P (1996) Construction of heteroplasmic mice containing two mitochondrial DNA genotypes by micromanipulation of single-cell embryos Methods in Enzymology 264 345-357

Marchington D, Hartshorne G, Barlow D and Poulton J (1997) Homopolymeric tract heteroplasmy in mtDNA from tissues and single oocytes: support for a genetic bottleneck American Journal of Human Genetics 60 408-416

*Marchington D, Hartshorne G, Barlow D and Poulton J (1998) Evidence from human oocytes for a genetic bottleneck in a mitochondrial DNA disease American Journal of Human Genetics 63 769-775

Marchington D, Barlow D and Poulton J (1999) Transmitochondrial mice carrying resistance to chloramphenicol on mitochondrial DNA: developing the first mouse model of mitochondrial DNA disease Nature Medicine 5 957-960

Matthews PM, Hopkin J, Brown RM, Stephenson JB, Hilton-Jones D and Brown GK (1994) Comparison of the relative levels of the $3243(A \rightarrow G)$ mtDNA mutation in heteroplasmic adult and fetal tissues Journal of Medical Genetics 31 41-44

Meirelles F and Smith L (1997) Mitochondrial genotype in a mouse heteroplasmic lineage produced by embryonic karyoplast transplantation Genetics 145 445-451

Molnar M and Shoubridge E (1999) Preimplantation diagnosis for mitochondrial disorders Neuromuscular Disorders 9521

*Poulton J and Turnbull DM (2000) 74th ENMC International Workshop: Mitochondrial Diseases 19-20 November 1999, Naarden, The Netherlands Neuromuscular Disorders 10 460-462

Poulton J, O'Rahilly S, Morten K and Clark A (1995) Mitochondrial DNA, diabetes and pancreatic pathology in Kearns-Sayre syndrome Diabetologia 38 868-871

*Sligh JE, Levy SE, Waymire KG, Allard P, Dillehay DL, Nusinowitz S, Heckenlively JR, MacGregor GR and Wallace DC (2000) Maternal germ-line transmission of mutant mtDNAs from embryonic stem cellderived chimeric mice Proceedings National Academy of Sciences USA 9714 461-14 466

Smeitink J and van den Heuvel L (1999) Human mitochondrial complex I in health and disease American Journal of Human Genetics 64 1505-1510

Suomalainen A, Majander A, Pihko H, Peltonen L and Syvanen AC (1993) Quantification of tRNA3243(Leu) point mutation of mitochondrial DNA in MELAS patients and its effects on mitochondrial transcription Human Molecular Genetics 2 525-534

Wardell T, Morris A, Wright C and Turnbull D (1999) Studies in Oocytes From a Female Infant with Pearson's Syndrome EUROMIT, Cambridge

Weber K, Wilson J, Taylor L, Brierley E, Johnson M and Turnbull D (1997) A new mtDNA mutation showing accumulation with time and restriction to skeletal muscle American Journal of Human Genetics 60 373-380

White S (1999) Molecular Mechanisms of Mitochondrial Disorders PhD Thesis, The Murdoch Institute, University of Melbourne

White S, Collins VR, Wolfe R, Cleary MA, Shanske S, DiMauro S, Dahl HH and Thorburn DR (1999a) Genetic counselling and prenatal diagnosis for the mitochondrial DNA mutations at nucleotide 8993 American Journal of Human Genetics 65 474-482

*White S, Collins V, Dahl H and Thorburn D (1999b) The level of mutant mtDNA in patients with mutations at NT8993 remains stable Journal of Inherited Metabolic Diseases 22 899-914 